\title{
24
}

\section{Water Engineering Without Borders: Opportunities for Solving Water System Problems Throughout the World}

\author{
Uzair (Sam) M. Shamsi, Michael Kang, Megan Campbell, Melissa \\ Day and Adam Shamsi
}

This chapter describes the water resources engineering and water system modeling opportunities throughout the world in various borderless non-governmental organizations (NGOs), such as engineers, water, architects, and doctors without borders. With a focus on Engineers Without Borders (EWB), the chapter provides the history, vision, and mode of operation of EWB. It clarifies the difference in EWB organizations in various countries with special emphasis on the United States and Canada. The distinct objectives of EWB-USA and EWB-Canada are compared. Project examples from both organizations are presented, especially those related to water, sanitation, and sustainability needs of the communities in various parts of the world. Lessons learned from these projects are shared and benefits of working on these projects, both for the students and the professionals, are summarized.

\subsection{Introduction}

Around the world, 783 million people do not have access to safe drinking water and 2.5 billion are without adequate sanitation facilities. Every day, nearly 6000 people who share our planet die from water-related illnesses, and the vast majority are children (Water For People, 2012). Only 12\% of

Shamsi, U.M., M. Kang, M. Campbell, M. Day and A. Shamsi. 2013. "Water Engineering Without Borders: Opportunities for Solving Water System Problems Throughout the World." Journal of Water Management Modeling R246-24. doi: 10.14796/JWMM.R246-24.

(C) CHI 2013 www.chijournal.org ISSN: 2292-6062 (Formerly in Pragmatic Modeling of Urban Water Systems. ISBN: 978-0-9808853-8-5) 
the world's population uses $85 \%$ of its water, and none of the $12 \%$ lives in developing countries. Most water resources engineers and urban water system modelers have worked on public works projects as government or company employees in their own countries. Nonprofit organizations and NGOs provide excellent professional development, a global perspective and humanitarian relief volunteer opportunities in developing countries, which have not been experienced by most engineers. The main purpose of this chapter is to elaborate on such opportunities for water resources engineers and urban water system modelers.

The United States Agency for International Development (USAID) and Canadian International Development Agency (CIDA), formed respectively by the United States and Canadian governments, have provided water and sanitation foreign aid programs in developing countries since the 1960s. In 1991, American Water Works Association (AWWA) founded Water for People, an international nonprofit development organization, to help people in developing countries improve the quality of their lives by supporting the development of locally sustainable drinking water resources, sanitation facilities and hygiene education programs (Water For People, 2012). Various without borders NGOs were founded throughout the world in early 2000. Wikipedia lists over 50 without borders organizations, with links and articles for each group (Wikipedia, 2012a). A partial list of water-related nonprofits and NGOs is.

- Engineers Without Borders, a series of independent NGOs involved in engineering related international development work; Water Without Borders;

- Architects Without Borders (ecologically sensitive and culturally appropriate design assistance to communities in need); Builders Without Borders (low impact development and green infrastructure for stormwater management);

- Doctors Without Borders (water related public health projects);

- Teachers Without Borders (water related public health education); and

- Students Without Borders (sustainable water solutions through education and technology).

Engineers Without Borders (EWB) is the name taken by distinct and separate non-governmental organizations (NGOs) in several different countries (see Table X.1 for examples). Although developed independently from each other and at different times, all these national organizations work to serve the needs of disadvantaged communities and people all over the world, and encourage engineering students and professionals to engage in work that addresses those needs. EWB-USA and EWB-Canada, described in this chapter, are good examples of such national organizations. The majority of the EWB 
organizations are strongly linked to academia and to students, with many of them being student led. Most focus on the water and sanitation needs of developing countries. In addition, many engineering firms support their national EWB organization and encourage their employees to engage with EWB; thus EWB organizations provide a convenient way for water resources engineers, professors and students to get involved.

Table 24.1 Engineers without Borders NGOs.

\begin{tabular}{l}
\hline \multicolumn{1}{c}{ Engineers Without Borders national organizations } \\
\hline Engineers Without Borders (Australia) \\
Ingénieurs Sans Frontières (Belgium) \\
Ingenieurs zonder Grenzen (Belgium) \\
Engineers Without Borders (Canada) \\
Ingeniører uden Grænser (Denmark) \\
Ingenieure ohne Grenzen (Germany) \\
Engineers Without Borders (India) \\
Ingegneria Senza Frontiere (Italy) \\
Engineers Without Borders (New Zealand) \\
Ingeniería Sin Fronteras (Spain) \\
Ingenjörer och Naturvetare utan Gränser (Sweden) \\
Engineers Without Borders (UK) \\
Engineers Without Borders (USA)
\end{tabular}

The first organizations to bear the EWB name were Ingénieurs sans frontières (ISF)-France, founded in the 1980s, and ISF-Spain and ISF-Italy, founded in the 1990s. EWB-Canada, one of the largest of the EWB organizations, was founded in 2000. EWB-UK was founded with the support of EWB-Canada in 2001 (Wikipedia, 2012b).

Due to data, time and budget constraints, EWB projects must use innovative, efficient and cost effective technical approaches. Most EWB projects require the use of the latest computational tools in the planning and design phases. For example, water and wastewater projects can greatly benefit from the new generation of intuitive and user friendly hydrologic and hydraulic $(\mathrm{H} \& \mathrm{H})$ models that can be quickly created from online public domain data. $\mathrm{H} \& \mathrm{H}$ modelers are therefore in high demand in EWB's water and sanitation projects.

\subsection{EWB-USA}

EWB-USA was founded in Colorado in 2001. As of 2011, it has approximately 12000 members and 350 projects in $>45$ developing countries (EWBUSA, 2012a). The vision of EWB-USA is that there be a world in which 
communities have the capacity to sustainably meet their basic human needs, and members have enriched global perspectives through the innovative professional educational opportunities. EWB-USA's mission is to support community driven development programs worldwide by collaborating with local partners to design and implement sustainable engineering projects, while creating transformative experiences and responsible leaders.

Working professionals (not just engineers) serve as technical mentors to EWB student chapters. Students receive a global perspective and hands-on engineering training. Professionals obtain a sense of accomplishment and get an opportunity to hire highly motivated students.

\subsubsection{EWB-USA Mode of Operation}

EWB-USA's typical mode of operation includes the following steps:

1. Projects are initiated by the student or professional chapters;

2. Chapters engage a developing community in resolving a particular infrastructure need that the community itself has identified. Each project requires a $5 \mathrm{y}$ commitment with the identified community. Most project communities are small remote villages but recently an inner city project was implemented in a densely populated urban setting in Rampur, India (Jedlicka, 2011a). This project was started by water resources engineers interested in solving the water and sanitation problems, but the local community identified sustainable energy as their most important need. In May 2012, a photovoltaic (PV) solar system was installed in an elementary school of the community to serve as a model and inspiration for other schools in the region. The community's next high priority need is treated drinking water. Community relationship and communication is an important and required part of EWB-USA projects. Figure 24.1 below shows a Pennsylvania State University senior student presenting an EWB-USA project to the students of a K-6 school in Rampur, India;

3. Chapters raise funds ( $\$ 50000$ to $\$ 100000)$ through donations, grants and fundraising events. An average project cost is about $\$ 50000$ US. Fundraising is a continuous process until the project is complete;

4. Students, under the guidance and supervision of their professional mentors, design a solution to the community's need. Projects involve students in every step of the process, enabling them to learn firsthand about the application of engineering 


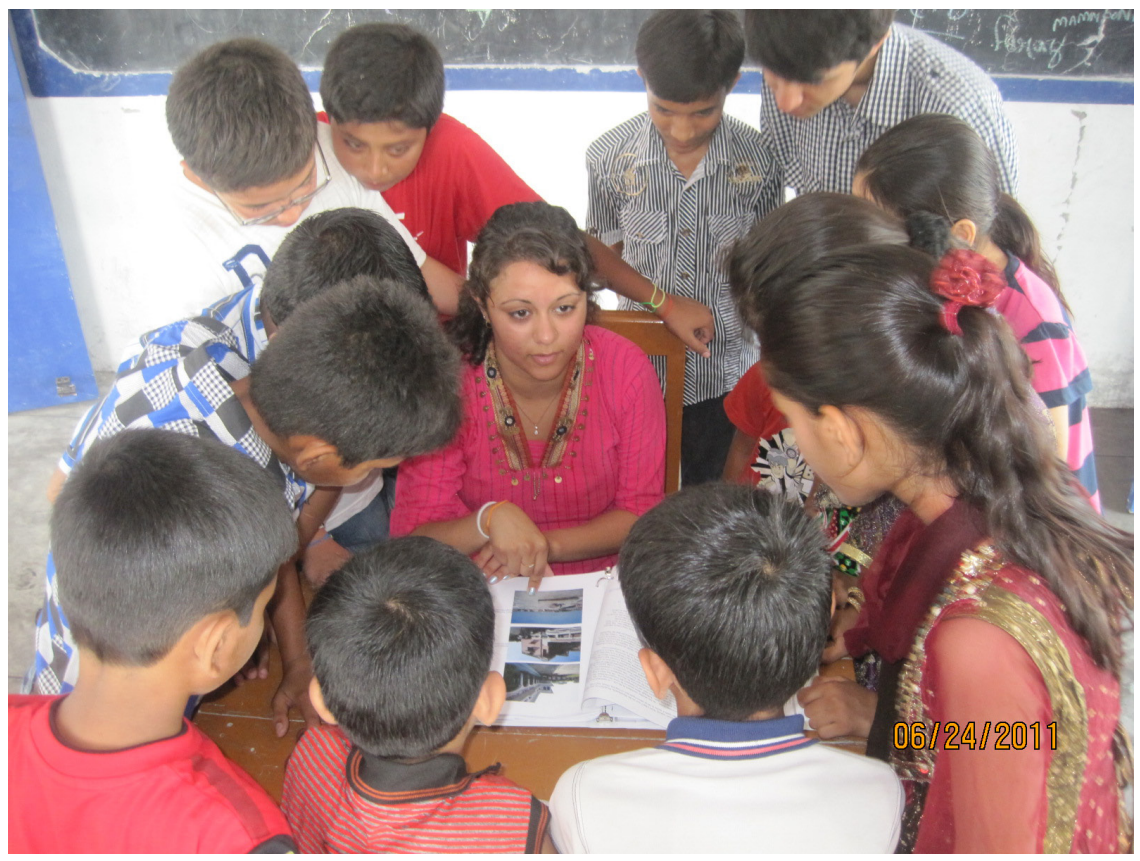

Figure 11.1 An example of community outreach, a required element of EWB-USA projects.

solutions to the problems of the developing world. Acting as designers, project managers, fundraisers and cultural ambassadors, students develop many skills to complement what they are learning in the classroom. The most hectic part of the project process is when students must submit the following nine reports to EWB-USA by set deadlines:

- Pre-Assessment (521 Report);

- Post-Assessment (522 Report);

- Alternatives Analysis (523 Report);

- Preliminary Design (524 Report);

- Pre-Implementation / Final Design (525 Report);

- Post-Implementation (526 Report);

- Program Closeout (527 Report);

- Pre-Monitoring (530 Report); and

- $\quad$ Post-Monitoring (531 Report);

5. The above reports are reviewed and approved by an EWBUSA project manager and require one or more revisions. The 
Pre-implementation 525 report, which includes the final design, is the most critical report for approval of project construction. This report is presented to and reviewed by a technical assessment committee (TAC) which almost always requires a resubmission; and

6. Student teams of four to six individuals travel to project sites with one or two professional mentors for at least two trips: site assessment and project implementation. Figure 24.2 shows a photograph from a 2011 site assessment trip by Carnegie Mellon University students to Rampur, India. In most implementation projects, travel team members take part in actual construction work with local volunteers and hired labor. Recently, a different implementation approach has been used in which a construction company was selected for implementing the design through a request for proposal (RFP) process and the travel team focused on the more important construction management and construction inspection $(\mathrm{CM} / \mathrm{CI})$ part of the project rather than taking the role of construction labor (Shamsi, 2011; Jedlicka, 2011b).

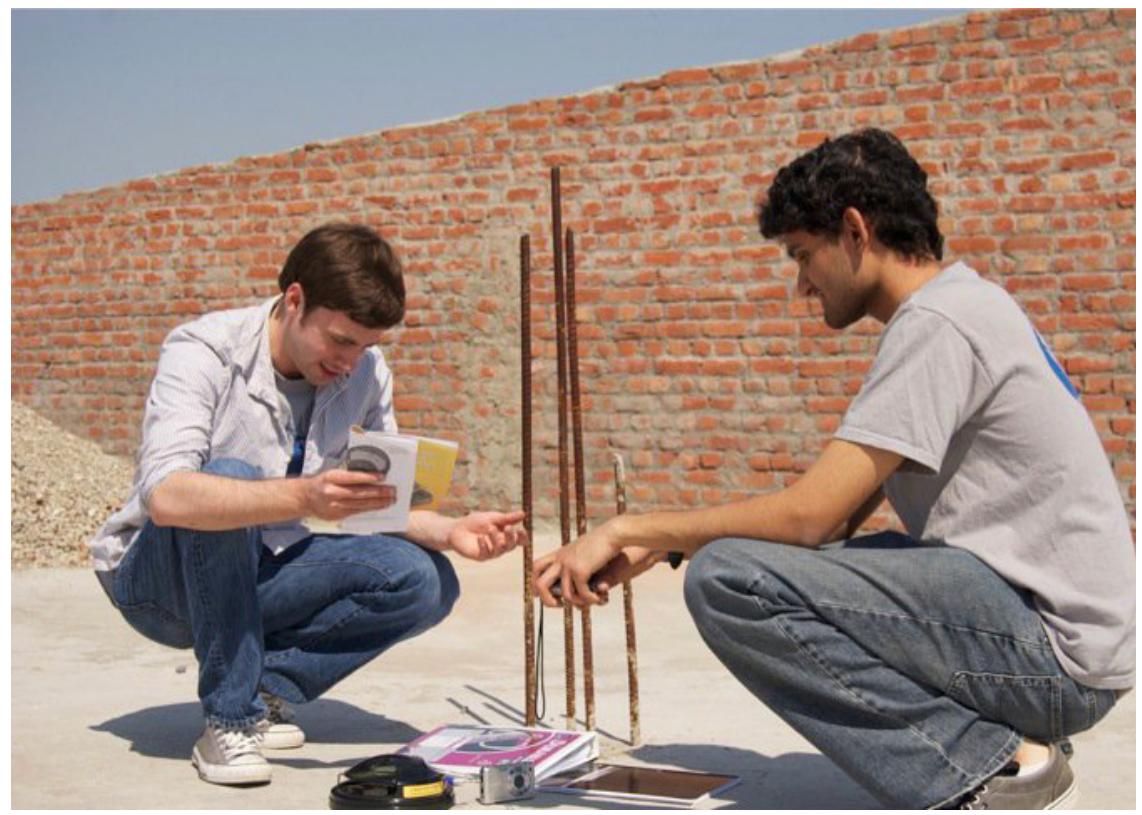

Figure24.2 Carnegie Mellon University students collecting design data in Rampur, India, during a site assessment trip. 


\subsubsection{EWB-USA Project Example: Tingo Pucará, Ecuador}

The information presented in this section is based on the work of the chapter co-author Melissa Day (EWB-USA, 2012b; Day, 2011).

Tingo Pucará is an indigenous small village community in Guangaje, located in the Cotopaxi province (Figure 24.3) in Ecuador. This is one of the poorest regions of the country with poor health, little possibility for income generation, and higher illiteracy rates than in other areas of the country. These factors are especially bad for the indigenous people of the province. In August 2009 , this particular community consisted of $\sim 30$ families (about 150 people) of indigenous Quechua heritage who have inhabited this region for centuries. In September 2010, the population had dropped to 26 families (about 99 people) mainly due to water supply issues.

The EWB Pittsburgh Professional Chapter (EWB-PPC) worked on this project with both The University of Pittsburgh (EWB-Pitt) and the Carnegie Mellon University (EWB-CMU) student chapters in Pittsburgh since 2008 (EWB-USA, 2012b; Day, 2011).

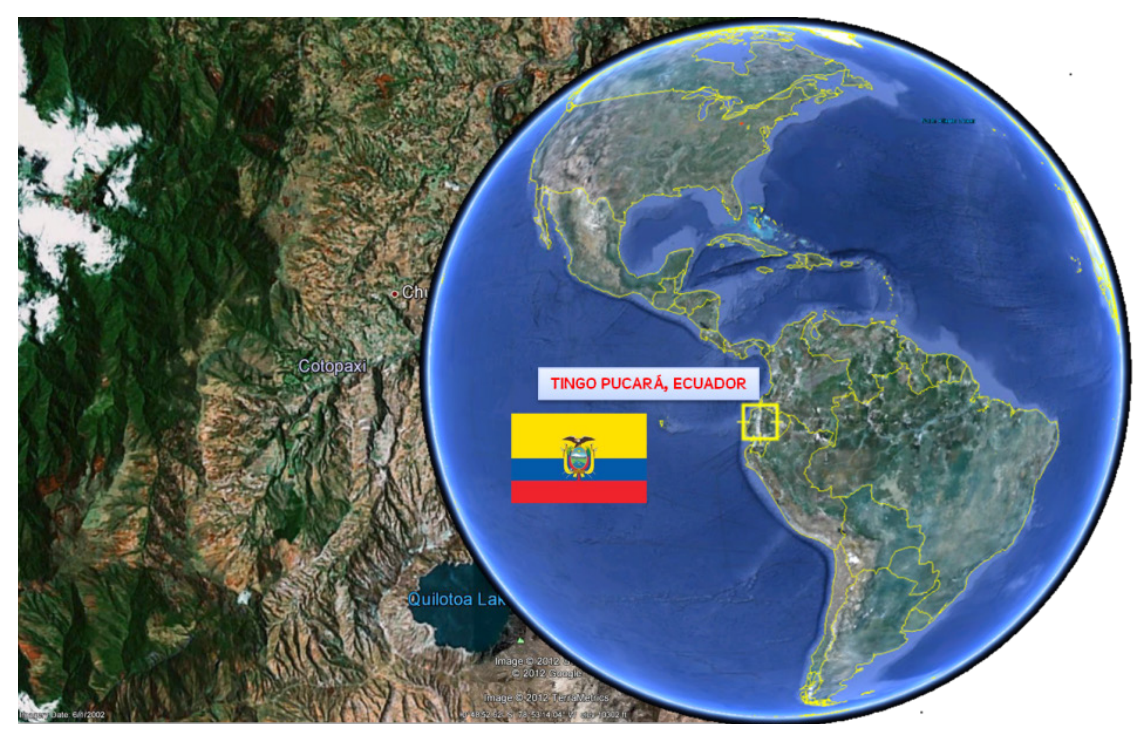

Figure 24.3 Tingo Pucará Location

\section{Project Objective}

The main objective of this project was to provide water supply to Tingo Pucará. 


\section{Community Need}

Much of Tingo Pucará water is taken from two newly installed rainwater catchment systems; if those are empty, the community also owns two sources of water from springs at the bottom of a mountain. As shown in Figure 24.4, The major source is called Quiloa, which is about $300 \mathrm{~m}$ (approximately 1000 feet) lower than the community center in elevation. A secondary source is about $30 \mathrm{~m}$ (approximately 100 feet) above Quiloa. These water sources had not been protected from fecal contamination.

After being collected at the springs, water is carried primarily by the women and children of the community back to their houses in open containers. This water is then stored in or outside the house in the same containers without proper disinfection. As a result, diarrhea is the most frequent cause of death in the community; the mortality rate is $>30 \%$ in children under five. They also have thirteen faucets from a gravity fed system from Guangaje, which serves $>500$ families in total throughout the region. Those in Tingo Pucará report that it rarely works for more than a few hours per month, however. During a September 2010 house survey, only one faucet had water.

\section{Project Scope}

A single-stage pumping system powered by grid energy was used to bring source water to a large tank at a high elevation point in the community. The following tasks were completed:

the intake system was constructed and finalized;

the sedimentation and pump tanks were constructed and finalized;

the pump house structure was built;

the intake area was fenced in to prevent animal waste contamination;

- the circular storage tank at community center was constructed and finalized;

- the final pipeline route was dug, and pipe and relay wire were laid; electrical lines were run down to the pump house;

the pump and electrcal equipment were installed; and the entire system was tested.

\section{Project Status}

In 2008, the team made contact with local organizations and collected information on design basics, community background and health conditions. Construction started in May 2011 and as of January 2012, this project was $95 \%$ complete. 


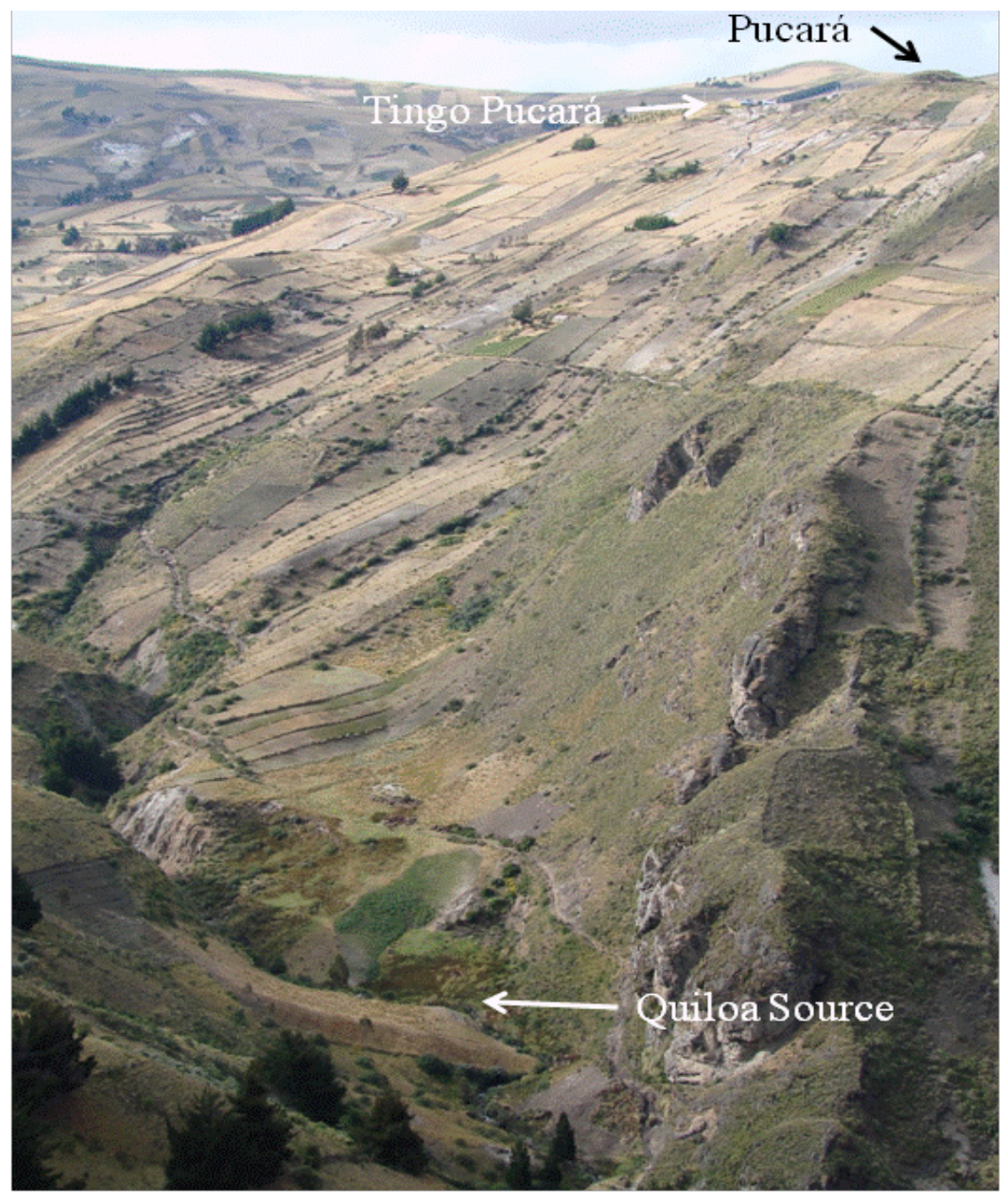

Figure 11.4 Tingo Pucará water supply source (EWB-USA, 2012b; Day, 2011).

\section{Project Results}

The project team has been monitoring the rain catchment systems installed during this project. During the August 2011 trip, the health survey indicated that thirteen households had access to the rain catchment system, or about $75 \%$ of the community. 


\section{Lessons Learned}

1. For trips to project site, plan extra days for contingency. Transportation issues, lost luggage, personal health conditions, and scheduling conflicts with local organizations can all delay the work progress;

2. Involve the community in planning because they are more knowledgeable about local resources than the travel team;

3. Bilingual travel team members are very valuable and should be sought out;

4. The impending design needs to be simple and robust; and

5. Teaming with a qualified in-country NGO, with members who are familiar with both the type of construction and type of culture you are involved with, is invaluable.

\subsection{EWB-Canada}

EWB-Canada was founded in 2000. EWB-Canada believes that poverty is the product of dysfunctional development aid, public service delivery, and community engagement systems that prevent people from realizing their full potential (EWB-Canada, 2012). Beating poverty means making those systems work. EWB-Canada is doing exactly that with a focus on rural African development. EWB-Canada incubates systemic innovations with an emphasis on people working with people to create lasting, scalable change that unlocks human potential.

The Water and Sanitation team of EWB-Canada is the focus of this section. This team is one of the five EWB-Canada African ventures which has been working on water and sanitation needs in Sub-Saharan Africa since 2006. EWB-Canada's African programs started with a volunteer-sending model in which graduates spent one to three years seconded to partner organizations, mostly local and international NGOs implementing traditional water and sanitation infrastructure projects. After several years of this approach it became apparent that the capacity increases in EWB-Canada's partner NGOs were not translating to the desired sustainable changes in the sector. EWB-Canada realized that NGOs are not a sustained means to service improvement. While they can help to fill financial voids, they cannot substitute the roles of local institutions in a meaningful or sustainable way to deliver services. Accordingly, the Water and Sanitation team shifted in 2009 to partnering with government officials and those international NGOs and donors with the strongest mandate to support sustainable water and sanitation service delivery. With experience of working in Zambia, Burkina Faso and Malawi, in 2010 the team narrowed 
its focus to the Malawian water and sanitation sector, in order to focus efforts at both district and national levels within one country.

\subsubsection{EWB-Canada Mode of Operation}

For EWB-Canada, workplace campaigns and city networks of professionals have important parts in EWB-Canada's advocacy campaigns for better Canadian aid. EWB-Canada believes that sustained access to water in Malawi requires more than the implementation of infrastructure. One time projects that provide water infrastructure or inputs for post-construction services fail to address systemic issues surrounding water infrastructure, allowing it to fall into disrepair. With both safe water and improved sanitation, the systemic challenge is one of sustained service provision at scale. A shift away from projectized approaches to the delivery of water and sanitation and towards the service delivery approach (SDA), enabling a functioning system for sustainability at scale, is gaining momentum among international funders, yet a clear set of fundable alternatives continues to elude the international sector.

EWB-Canada's African Program staff build the strong relationships and partnerships necessary to have influence, to gain and share the knowledge needed to challenge the assumptions being made by the sector, and to make it easier for key sector players to act on new knowledge by providing tools, by capacity building, and through other elements of support. Furthermore the team acts as a conduit for better information flow between the three levels, strengthening the ability of the sector overall to learn and to adapt to what is needed to provide sustainable services in water and sanitation.

\subsubsection{EWB-Canada Project Example: Malawi, Africa}

The information presented in this section was provided by the Chapter coauthors Michael Kang and Megan Campbell.

\section{Project Objective}

The EWB-Canada Water and Sanitation team does not run projects, particularly in the traditional sense of initial infrastructure provision. Rather, the team implements the following initiatives to support major shifts necessary for the Malawian Water and Sanitation sector to strengthen its ability to provide services over a $10 \mathrm{y}$ period:

define the roles of key actors in the system and assess their capacity needs; invest in the capacity of permanent institutions; 
invest in the sector's capacity to learn; and strengthen relationships of key officials.

\section{Project Scope}

The EWB-Canada Water and Sanitation team's project scope is the entire water and sanitation sector in Malawi. The scope of change EWB-Canada aims for in the sector is essentially a change in thinking, discourse and norms of behavior in the sector.

Project Results Example 1: Using Area Mechanics for Post-Construction Services In Mulanje district, the African Development Bank (ADB) and a Malawian NGO are each taking action to implement an area mechanic network. Currently there is little incentive in the sector for either of these actors to heavily involve the local government, who is the only permanent institution in the equation with a conceivable mandate to manage the network in the future. This situation threatens the sustainability of this intervention for post-construction services because there is no exit strategy being proactively pursued that smartly considers the roles and capacities of the district over time - when the projects phase out, the area mechanic network may lose support and dissolve. Having partnered with the ADB, the Malawian NGO, and the Mulanje District Council, EWB-Canada is in a position to broker and strengthen dialog between these actors and put the issue of appropriate role definition on their agenda. At the same time, EWB-Canada is working directly with the District Council to develop tools and approaches that enable the district to take on the role of supporting area mechanics.

\section{Project Results Example 2: Decision Support Systems for Local Government}

It is a widely held conclusion in the sector that government, particularly local government, should be at the forefront of monitoring efforts. In support of this, EWB-Canada has invested resources over the past two years in helping local government staff develop innovative and appropriate solutions, including new data collection approaches, targeted planning tools, and custom mapping software. EWB-Canada has also directly provided hundreds of person hours of hands-on training for local government staff. Elements of this work are now being integrated into nationally mandated approaches for water supply and sanitation monitoring, and the work has gained significant recognition both within Malawi and internationally.

\section{Challenges and Lessons Learned}

1. Limitations of the volunteer-sending model: EWB-Canada has found that a volunteer-sending model has advantages in that the 
organization can leverage low cost, high value human resources from the Canadian engineering sector. However, this model presents challenges in terms of the continuity of knowledge and relationships in the Malawi sector, as many of the assets are based on trust and relationships rather than bringing large resources into the sector;

2. Benefits of being financially neutral: On the other side of the limitations of a low cost volunteer model, the fact that EWBCanada does not bring project resources into the sector allows the organization to be more neutral than most in the sector, and ensure that the value of their role is understood in terms of the ideas and know-how they have, rather than the money they bring;

3. Challenges with entrenched sector politics: The service delivery concept is one that has proven difficult to spread in the sector. This is not because of the concept itself, but rather due to the structure that dominates sector interventions: constrained project budgets and contracts that define success in terms of project outputs;

4. Challenges holding different identities depending on the partner and the change being addressed: Given that each subset of the sector (district, national government, donors, communities and NGOs) have different incentives, and view the sector differently, each values different parts of EWB-Canada's work differently;

5. Challenges of setting goals for scale: Given EWB-Canada's recognition of the need for the transformation cycle, setting goals for scale has proven challenging. There is a need to find a balance between quality (acknowledging that institutional capacity limitations will mean that any idea will lose some quality at scale) and sector wide change (acknowledging that any one, isolated, idea, however effective, has limited impact on the sector wide challenges if it cannot lead to change at scale); and

6. Challenges of creating a more robust learning sector and supporting collective impact: EWB-Canada's impact in the sector is limited by its ability to translate its systemic approach into improved capacities in the sector's ability to learn.

\section{Project Status}

The project began in 2007 and expects to achieve the aforementioned changes in the sector by 2015 . 


\subsection{Conclusions}

Water related nonprofit organizations and NGOs provide water resources engineering and urban water system modeling volunteer opportunities, in needy and under-privileged communities in developing countries, for those who have volunteer time and a desire to change the world on community at a time. There are several NGOs to choose from in most developed countries but EWB organizations seem to be ideally suited for water resources engineers, professors and students to get involved.

EWB-USA and EWB-Canada have different modes of operation. Whereas EWB-USA undertakes infrastructure construction world-wide, EWB-Canada focuses on policy changes in Africa. Despite these differences, excitement, passion, discipline and altruism are words which describe the efforts of the EWB teams from both the countries involved in the projects of needy communities far from their homeland. Regardless of their origin, all EWB projects benefit both the students and the professionals.

EWB student chapters acquire the determination to create a better world through engineering while developing their own career skills in engineering. Students get free hands-on on-the-job training, international travel experience, and a global perspective. Some students can start their managerial role as eighteen years old freshmen. As the student project managers, they learn to communicate effectively with people of different backgrounds, oversee a variety of planning tasks, and create and adhere to a realistic project budget and timetable. With this real world training often absent in class rooms, the students certainly will be able to carry these skills into their future engineering career. Volunteer work enhances student resumes and improves their job prospects. EWB project involvement also offers employment opportunities for the students through their professional mentors.

Professionals get a global perspective, sense of accomplishment, and an opportunity to mentor the students and build relationships with the academic community. EWB project involvement provides the professionals an excellent opportunity to hire highly motivated students. Professionals often realize that the sense of accomplishment helping needy people or communities is much more profound than the rewards of compensated employment.

\section{Acknowledgments}

Tingo Pucará project information was provided by Melissa Day (EWB-USA, 2012a; Day, 2011). Malawi project information was provided by Michael Kang and Megan Campbell. Rampur, India project information was provided 
by Sam Shamsi and Adam Shamsi, a student at The University of Pittsburgh. Final proofreading and editing was done by Adam Shamsi. The authors would like to thank the following people for their help or contribution to this paper:

- Dr. Kim Irvine, Professor, Buffalo State College;

- Dr. Barry Adams, Professor Emeritus, University of Toronto;

- Amir Allana, President, EWB Canada Chapter, University of Toronto;

- Jennifer Lehane, Planning Associate and EWB-Baker board member at Michael Baker Corporation, Oakland, California; and

- Josh Jedlicka, Civil Engineer at CDMSmith and member of EWB-USA Chapter of Pittsburgh Professionals.

\section{References}

Day, M. (Ed.). 2011. “Tingo Pucará Development Document 525 Pre-Implementation Report." EWB-USA.

EWB-USA. 2012a. Web Site. www.EWB-usa.org

EWB-USA. 2012b. Projects > Locate a Project. Web Site. www.EWB-usa.org. Site Visited on September 10, 2012

EWB-Canada. 2012. Web Site. www.ewb.ca

Jedlicka, J. 2011a. "Powering Symbiosis: Engineers Without Borders Uses Solar Power in India." ASCE News, American Society of Civil Engineers Pittsburgh Section Newsletters. October 2011.

Jedlicka, J. 2011b. "Powering Symbiosis: Engineers Without Borders at Carnegie-Mellon University Hard at Work in India." Pittsburgh Engineer, Quarterly Publication of the Engineers' Society of Western Pennsylvania. Fall 2011.

Shamsi, U.M. 2011. "Project Symbiosis: Sustainable Energy for Schools in India." Compass Article, Michael Baker Corporation. September 2011.

Water for People. 2012. Home Page http://www.waterforpeople.org/. Site Visited on July 9, 2012.

Wikipedia. 2012a. "List of Without Borders Organizations." http://en.wikipedia.org/wiki/ List_of_Without_Borders_organizations. Site Visited on July 9, 2012.

Wikipedia. 2012b. "Engineers Without Borders.” http://en.wikipedia.org/wiki/Engineers Without_Borders. Site Visited on April 23, 2012. 
